\title{
Space weather benchmarks on Japanese society
}

\author{
Mamoru Ishii ${ }^{*} \mathbb{0}$, Daikou Shiota' ${ }^{1}$, Chihiro Tao ${ }^{1}$, Yusuke Ebihara², Hitoshi Fujiwara ${ }^{3}$, Takako Ishii ${ }^{2}$

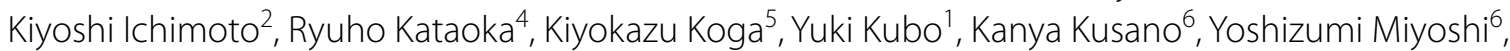 \\ Tsutomu Nagatsuma', Aoi Nakamizo', Masao Nakamura7', Michi Nishioka', Susumu Saito ${ }^{8}$, Tatsuhiko Sato ${ }^{9}$, \\ Takuya Tsugawa' ${ }^{1}$ and Shigeo Yoden ${ }^{10}$
}

\begin{abstract}
We surveyed the relationship between the scale of space weather events and their occurrence rate in Japan, and we discussed the social impact of these phenomena during the Project for Solar-Terrestrial Environment Prediction (PSTEP) in 2015-2019. The information was compiled for domestic users of space weather forecasts for appropriate preparedness against space weather disasters. This paper gives a comprehensive summary of the survey, focusing on the fields of electricity, satellite operations, communication and broadcasting, satellite positioning usage, aviation, human space activity, and daily life on the Earth's surface, using the cutting-edge knowledge of space weather. Quantitative estimations of the economic impact of space weather events on electricity supply and aviation are also given. Some topics requiring future research, which were identified during the survey are also described.
\end{abstract}

Keywords: Space weather, Benchmark, Extreme event, Societal impact, Economic impact estimation

\section{Main text Introduction}

Serious social impacts of space weather are quite rare, but the effects can be significant. The most severe space weather event on record is known as the Carrington Event, which occurred on September 1-2, 1859. At that time, some wired telegraph stations were damaged by geomagnetically induced current (GIC). The insurance company Swiss Re estimated the present economic loss in each region in the world for a space weather event of a similar scale to the Carrington Event (Swiss Re 2014). They found that the economic loss in high-latitude countries would be equivalent to that of the 2011 earthquake off the Pacific coast of Tohoku, Japan.

The United States (US) has some of the most advanced measures to prepare for the social impact of disasters due

\footnotetext{
${ }^{*}$ Correspondence: mishii@nict.go.jp

${ }^{1}$ National Institute of Information and Communications Technology

(NICT), Koganei, Tokyo, Japan

Full list of author information is available at the end of the article
}

to extreme space weather. They assigned space weather as one of the natural hazards equivalent to an earthquake, flood, or human pandemic in the US Strategic National Risk Assessment in 2011. The Space Weather Operations, Research, and Mitigation (SWORM) Working Group was established in 2014 and has discussed the strategy and national plan. Their action plan was published by the White House in 2015 (US National Science and Technology Council 2015a, 2015b). As one of the results of the action plan, benchmarks for extreme space weather events have been discussed, and "Space Weather Phase 1 Benchmarks" was published by the White House in June 2018 (US National Science and Technology Council 2018). Toward refining these Phase 1 benchmarks, the Institute for Defense Analyses (IDA) reported the culmination of the next step of space weather benchmark efforts (US Science and Technology Policy Institute 2019). In addition, the international workshop "Space Weather as a Global Challenge" has been held since 2016 as a forum for discussing globally coordinated and consistent space weather services. Japan hosted the third 
workshop at the Japanese embassy in Washington D.C. in July 2018. Steps to ensure national preparedness for space weather have also been taken in some other countries, such as the United Kingdom (UK Cabinet Office 2015), and this global trend has been accelerating since 2016.

In Japan, a report entitled "Assessment of the impact of space weather phenomena on society for scientific suggestions" (hereafter "PSTEP report") was prepared in 2020 as part of the Project for Solar-Terrestrial Environment Prediction (PSTEP) (e.g., Kusano et al. submitted to this issue). PSTEP is a nationwide research collaboration supported by a Grant-in-Aid for Scientific Research on Innovative Areas from the Ministry of Education, Culture, Sports, Science and Technology (MEXT), Japan. There are two main goals of this project: to answer some of the fundamental questions concerning the solar-terrestrial environmental system and to contribute to building a next-generation space weather forecast system to prepare for disasters due to severe space weather.

Japan is located in the mid-latitude region, in which the impact of severe space weather, e.g., GIC, has been ignored for a long time. However, the results of a series of PSTEP research activities indicated that the effect of GIC in Japan could be significant in some cases. These results require us to change our way of thinking.

In addition, we have been making advances in solarterrestrial physics for studying the mechanism of phenomena and the connection/interaction among the Sun, solar wind, magnetosphere, ionosphere, and atmosphere, while investigations of the quantitative impact of these phenomena on society and the communication with society about their impact have been insufficient. As a result, people in industry are not interested in space weather or do not wish to confront the problem. One of the purposes of the PSTEP report is to give correct information to people in different fields to help them make appropriate preparations against space weather. In the PSTEP report, we discussed the impact of space weather on Japanese society, referring to the latest knowledge of solar-terrestrial physics, as well as possible disasters and the economic impact in the electric power and aviation fields. We also recognize that this report, summarizing a wide range of topics on the potential effects of space weather, is still incomplete and requires future improvements in the detail.

Here, we report the essence of the detailed discussion in the PSTEP report, which has been rewritten as a scientific paper. Section "Method" describes the methodological approach, Sect. "Definition of scale of space weather phenomena" defines the scale of space weather phenomena, Sect. "Estimation of effect of space weather on society" evaluates the scale of social impacts, then Sect. "Evaluation of economic impact" describes the economic impact on the electric power and aviation fields. Identified future research issues that must be tackled in order to provide an accurate evaluation of the effect of space weather are listed in Sect. "Required research topics", and Sect. "Summary" summarizes this paper.

\section{Method}

The social impact of space weather involves a chain of multiple space weather phenomena (Fig. 1). Therefore, we constructed benchmarks by the following two steps. First, scales of individual space weather phenomena were defined by their occurrence probability. Then, the impact of space weather phenomena on each field of Japanese society was evaluated.

The scale of each space weather phenomenon was defined on the basis of a review of previous research and new analysis. We focused on phenomena with scales that correspond to occurrence probabilities of once per 1, 10, 100, and 1000 years. We first tried classifying all phenomena into a single category, although not all phenomena are necessarily caused by or linearly related to solar disturbances, e.g., enhancement of outer radiation belt electrons and occurrences of the ionospheric sporadic E-layer and plasma bubbles. Therefore, we defined the event scale for each phenomenon. Since the scales of the phenomena that occur once per 100 and 1000 years are based on extrapolated estimations, physical-based discussions have been added wherever possible.

We examined the possible social impact of a huge space weather event for the fields of electric power, satellite operation, radio communication and broadcasting, positioning usage, aviation operation, manned space activity, and daily life on the Earth's surface. The PSTEP report lists social hazards that occurred in the past (not given in this paper) and gives the social impacts for different occurrence probabilities similar to those used to classify the scales of phenomena. This evaluation is documented for each field so that industries whose business could be affected by space weather can comprehensively grasp the effects relevant to them.

We hold the Space Weather Users Conference several times every year to have a dialogue with people from industry who use and/or are interested in space weather information. This provides us with an opportunity to exchange progress in research from scientists (seeds) and to evaluate the social impact of space weather phenomena and the information required by industries (needs). Comments received regarding the social impact assessment are compiled in this evaluation. 


\section{Definition of scale of space weather phenomena}

Table 1 summarizes the estimated scale of space weather phenomena. The estimation method and references are explained hereafter.

\section{Solar flares}

The peak value of X-ray flux observed by Geostationary Operational Environmental Satellite (GOES), i.e., the flare class, and the total flare energy are defined as flare size indices.

The peak flux of solar flares follows a power-law distribution (e.g., Dennis 1985). Gopalswamy (2018) calculated the cumulative number distribution of the flare peak flux in the 1-8 $\AA$ wavelength band observed by satellite from January 1969 to December 2016. By fitting a Weibull function to the distribution, flare levels corresponding to once per 10, 100, and 1000 years were estimated and extrapolated as X12, X44, and X101, respectively.

It has been reported that a solar-type star produces "superflares", which are two or more orders of magnitude larger than the largest flare observed from the Sun. A large number of superflares have been detected in the photometric observation of solar-type stars. From the distribution observed by Kepler space telescope, the occurrence frequency of flares with energy of $10^{34}$ ergs or more is once per 800 to 5000 years (Maehara et al. 2012). According to the occurrence frequency $N$ year $^{-1}=10^{31} / E$, where $E$ is solar energy in the unit of erg (e.g., Fig. 17 of Notsu et al. 2019), the flare energies with probabilities of once per 10, 100, and 1000 years were estimated to be $10^{32}, 10^{33}$, and $10^{34} \mathrm{erg}$, respectively. However, there is no consensus on the possibility that superflares will occur from the current Sun, with opinions divided among experts.

The largest solar flare observed so far is the X28 class flare, which occurred on November 4, 2003. X44, which is the flare level corresponding to once per 100 years, and X101, corresponding to once per 1000 years, were extrapolated from the existing observations. The possible solar flare scale was estimated to be X75 (Miyake et al. 2019), assuming that the maximum free energy stored in the largest active region generated in the 24th solar cycle is released most efficiently and considering the relationship between magnetic flux and free energy in the solar active region and the relationship between the free energy and flare class, i.e., GOES flux, obtained after 2012 based on observation by the Solar Dynamics Observatory (SDO). The largest active region recorded so far is AR 14886 of $6132 \mathrm{MSH}$ (1 MSH=1 millionth of a solar hemisphere $=6.087 \times 10^{16} \mathrm{~cm}^{2}$ ) observed at the Royal Greenwich Observatory in April 1947 (e.g., Aulanier et al. 2013). Since the free energy is proportional to the $3 / 2$ th power of the sunspot area assuming the same vertical and horizontal extent, the estimated scale becomes X250. Although the X75 estimation based on the 24th solar cycle would be an underestimate whereas X250 would be an overestimate due to simplification in the estimation, it has been estimated that flares of at least X101 can occur at the large sunspots that have been observed so far.

\section{Coronal mass ejection (CME)}

Since the most dominant energy of CME is kinetic energy, the scale of CME was defined by the CME velocity and kinetic energy. Extreme CME events may also accompany extreme solar wind and interplanetary magnetic field (IMF) disturbances to cause extreme geomagnetic disturbances. The extreme solar wind and IMF reaching the Earth might result from extreme CME propagation into background solar wind in the inner heliosphere, so its occurrence condition needs more detailed study. Here, as a first step toward such study, we focus on the occurrence rate of CME as a function of its velocity or kinetic energy.

We refer to the results obtained by Gopalswamy (2018), who derived the cumulative occurrence distribution of CME velocity and kinetic energy from the Solar and Heliospheric Observatory (SOHO)/Large Angle and Spectrometric COronagraph experiment (LASCO) observation in 1996-2016. The distribution was fitted with Weibull functions, then the CME velocities corresponding to occurrence probabilities of once per 1, 10, 100, and 1000 years were estimated to be $2000,3000, \sim 4000$, and $\sim 5500 \mathrm{~km} / \mathrm{s}$, respectively. The estimated kinetic energy of $9.8 \times 10^{33} \mathrm{erg}$ for the occurrence probability of once per 1000 years is just 2-3 times higher than that for the recorded event of $4.2 \times 10^{33} \mathrm{erg}$ (Gopalswamy 2018). The important factors determining the magnitude of a magnetic storm are whether a CME launched from the Sun actually reaches the Earth, the magnitude of the southward magnetic field component of the CME passing through the Earth, and how long the CME continues to pass through the Earth. Note also that a CME interacts with the background solar wind, causing it to accelerate or decelerate before reaching the Earth after its launch from the corona, where the CME speed is observable by SOHO/LASCO.

\section{Solar energetic particles (SEPs)}

The SEP phenomenon is a rapid increase in the number of energetic particles from $\mathrm{MeV}$ to $\mathrm{GeV}$ due to solar flares and CME. The scale of SEP events generally refers to a maximum particle intensity above $10 \mathrm{MeV}$ observed by the GOES satellite, or the flow rate derived as a time 


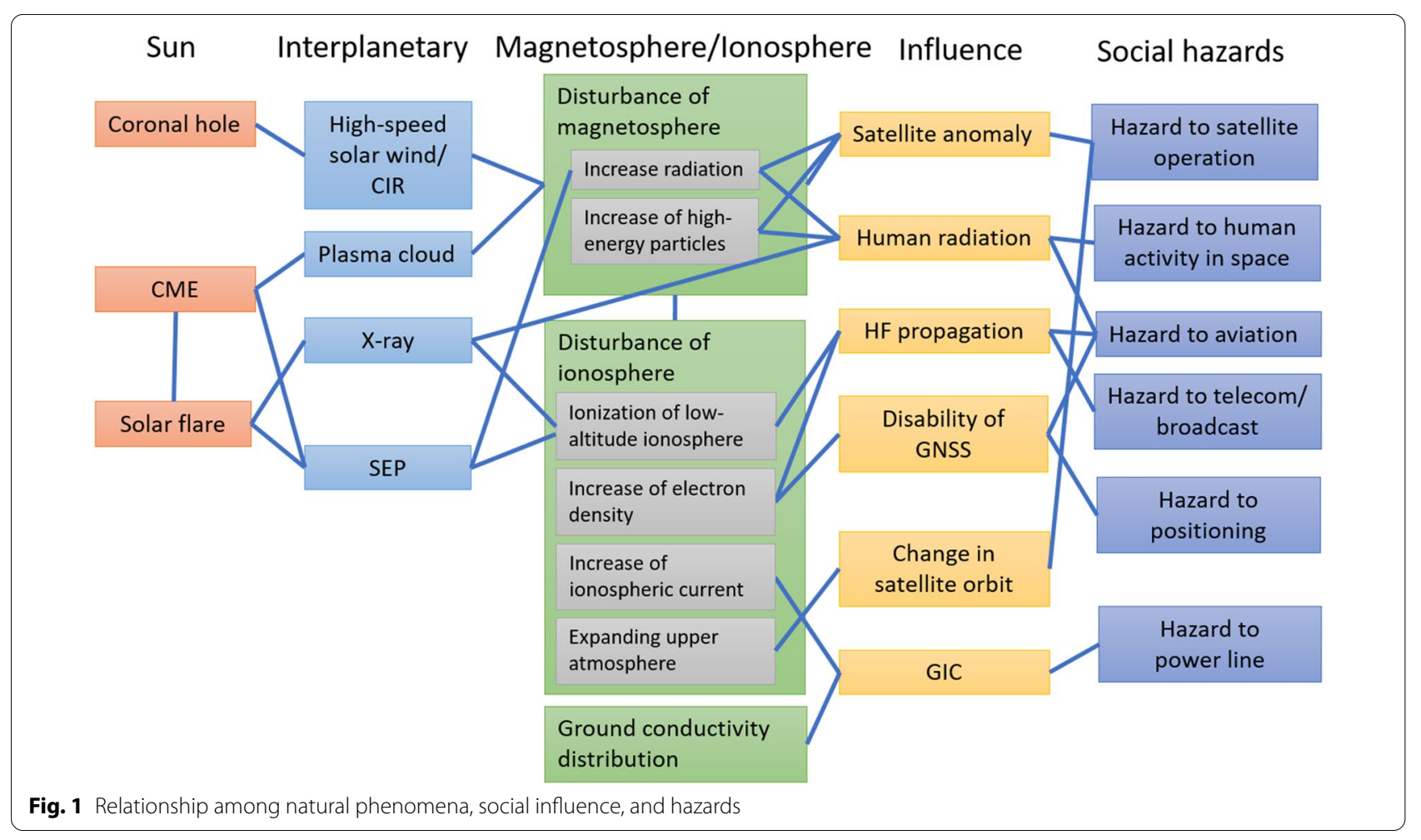

integration of the number of particles over an entire event period. When an increase in the count due to secondary particles generated during the precipitation of SEPs into the atmosphere is detected by a neutron monitor on the ground surface, the event is called ground level enhancement (GLE). Not all large-scale SEP phenomena trigger GLE. Not only SEP flux of $10 \mathrm{MeV}$ or more, but also energy dependence is important for GLE occurrence. Here, the SEP event size is determined by a SEP flux of above $10 \mathrm{MeV}$ and the occurrence of a GLE event.

Gopalswamy (2018) obtained the cumulative frequency distribution of the flow rate of SEPs with energies of $10 \mathrm{MeV}$ or more by using the $216 \mathrm{SEP}$ phenomena observed from November 1987 to January 2016 and fitting with a Weibull function. The magnitudes of SEP phenomena that occur once per 100 and 1000 years were estimated to be 2.4 to $5.1 \times 10^{10}$ and 3.8 to $14 \times 10^{10} \mathrm{~cm}^{-2}$, respectively.

The background count of neutron monitors during the time period when events do not occur fluctuates in the long term. The scale of GLE is defined by the rate of increase (unit: \%) from the background when the phenomenon occurs. Here, we referred to the eventintegrated intensity (EII, unit \%*h) obtained by Asvestari et al. (2017), which corresponds to the flow rate of the SEP phenomenon obtained by integrating the rate of increase over the entire event time. By fitting a power function to the cumulative occurrence distributions of 72 GLEs observed during 77 years from 1942 to 2019, the phenomena with a frequency of occurrence of once per 10,100 , and 1000 years were estimated to have EII $>190$, 6,600 , and $223,000 \% * h$, respectively.

\section{Solar radio burst}

For the once-per-100-year benchmarks for solar radio bursts, we referred to "Space Weather Phase 1 Benchmarks" reported by the US National Science and Technology Council (2018). Very high frequency (VHF), ultra-high frequency (UHF), and microwave frequencies were selected as the frequencies affected by solar radio bursts in the report. The F10.7 index and widely used frequencies employed by the Global Positioning System (GPS) are also included in the report. These once-per100-year benchmarks were estimated by interpolation of the power-law function fitted to long-term observations compiled by the National Geophysical Data Center over 40 years (Nita et al. 2002). A theoretical maximum of the solar radio burst intensity has not yet been discussed, which is identified as a topic of future research in this report. 
Table 1 Estimation of scale of space weather events with occurrence probabilities of daily to several times per year, once per year, and once per 10, 100, and 1000 years

\begin{tabular}{|c|c|c|c|c|c|c|}
\hline Phenomena & Parameter & $\begin{array}{l}\text { Daily-several } \\
\text { per year }\end{array}$ & Once per year & Once per 10 years & Once per 100 years & Once per 1000 years \\
\hline \multirow[t]{2}{*}{ Solar flare } & X-ray peak flux & $\mathrm{M} 1-\mathrm{X} 1$ & $X 7.6$ & $\times 12$ & X44 & X101 \\
\hline & Energy [erg] & $<2.0 \times 10^{30}$ & $1.0 \times 10^{31}$ & $1.0 \times 10^{32}$ & $1.0 \times 10^{33}$ & $1.0 \times 10^{34}$ \\
\hline \multirow{2}{*}{$\begin{array}{l}\text { Coronal mass ejec- } \\
\text { tion (CME) }\end{array}$} & Velocity [km/s] & $250-450$ & 2000 & 3000 & $3800-4500$ & $4700-6600$ \\
\hline & Kinetic energy [erg] & & & & $4.4 \times 10^{33}$ & $9.8 \times 10^{33}$ \\
\hline \multirow[t]{2}{*}{$\begin{array}{l}\text { Solar energetic } \\
\text { particles (SEPs) }\end{array}$} & $\begin{array}{l}\text { Fluence }(\geq 10 \mathrm{MeV}) \\
{\left[10^{10} \mathrm{~cm}^{-2}\right] \text { at GEO }}\end{array}$ & & $\sim 0.1$ & $\sim 1.0$ & $\sim 2.4-5.1$ & $\sim 3.8-14$ \\
\hline & Ell [\%•h] & & & $\sim 190$ & $\sim 6600$ & $\sim 223,000$ \\
\hline \multirow[t]{5}{*}{ Solar radio burst [sfu] } & $\begin{array}{l}\text { Very high frequency } \\
(\mathrm{VHF}, 30-300 \mathrm{MHz})\end{array}$ & & & & $<2.8 \times 10^{9}$ & \\
\hline & $\begin{array}{l}\text { Ultra-high frequency } \\
(\text { UHF, 300-3000 MHz) }\end{array}$ & & & & $<1.2 \times 10^{7}$ & \\
\hline & GPS (1176-1602 MHz) & & & & $<1.2 \times 10^{7}$ & \\
\hline & F10.7 (2800 MHz) & & & & $<1.3 \times 10^{7}$ & \\
\hline & $\begin{array}{l}\text { Microwave (4000- } \\
20,000 \mathrm{MHz})\end{array}$ & & & & $<3.7 \times 10^{7}$ & \\
\hline $\begin{array}{l}\text { Variations of relativis- } \\
\text { tic electron flux of } \\
\text { the outer radiation } \\
\text { belt }\end{array}$ & $\begin{array}{l}\text { Electron flu- } \\
\text { ence }(>2 \mathrm{MeV}) \\
{\left[10^{10} \mathrm{~cm}^{-2} \mathrm{sr}^{-1}\right] \text { at }} \\
\text { GEO }\end{array}$ & $\sim 0.1$ & $\sim 0.6$ & $\sim 3.0$ & $\sim 10$ & $\sim 26$ \\
\hline Magnetic storm & Dst index [nT] & & $\sim-220$ & $\sim-450 \pm 30$ & $\sim-650 \pm 110$ & $\sim-930$ \\
\hline \multirow[t]{2}{*}{ Substorm } & AL index [nT] & & $\sim-3700$ & $\sim-4100$ & $\sim-4100$ & $\sim-4200$ \\
\hline & SML index [nT] & -460 & -3000 & -4000 & -5000 & -5900 \\
\hline \multirow{3}{*}{$\begin{array}{l}\text { Total electron con- } \\
\text { tent (TEC) }\end{array}$} & @Tokyo [TECU] & & $\geq 90$ & $\geq 130$ & $\geq 190$ & \\
\hline & @Kagoshima [TECU] & & $\geq 110$ & $\geq 160$ & $\geq 230$ & \\
\hline & @Hokkaido [TECU] & & $\geq 70$ & $\geq 105$ & $\geq 150$ & \\
\hline \multirow[t]{2}{*}{$\begin{array}{l}\text { Dellinger phenom- } \\
\text { enon }\end{array}$} & $\begin{array}{l}\text { Absorption [dB] } \\
\text { @6.6 MHz (long- } \\
\text { circuit) }\end{array}$ & & $\sim 71$ & $\sim 83$ & $\sim 93$ & $\sim 100$ \\
\hline & Event duration [h] & & $0.6-1.3$ & $1.8-3.6$ & $4.0-6.8$ & $7.4-11.9$ \\
\hline \multirow[t]{4}{*}{$\begin{array}{l}\text { Sporadic } \\
\text { E-layer }\end{array}$} & $\begin{array}{l}\text { Frequency propagat- } \\
\text { ing } 1,000 \mathrm{~km}[\mathrm{MHz}]\end{array}$ & & 100 & 110 & $\geq 130$ & \\
\hline & $\begin{array}{l}\text { Frequency propagat- } \\
\text { ing } 2,000 \mathrm{~km}[\mathrm{MHz}]\end{array}$ & & 130 & $\geq 180$ & $\geq 180$ & \\
\hline & $\begin{array}{l}\text { Duration for } \\
\text { foEs }>13.3 \mathrm{MHz}[\mathrm{h}]\end{array}$ & & $\sim 3$ & $\sim 5$ & & \\
\hline & $\begin{array}{l}\text { Duration for } \\
\text { foEs > } 18 \mathrm{MHz}[\mathrm{h}]\end{array}$ & & $\sim 1-2$ & $\sim 3$ & & \\
\hline Plasma bubble & Event duration [h] & & $4-5$ & 6 & & \\
\hline \multirow[t]{3}{*}{$\begin{array}{l}\text { Polar cap absorption } \\
\text { (PCA) }\end{array}$} & $\begin{array}{l}\text { Invariant latitude, day } \\
@ 6.6 \mathrm{MHz} 10 \mathrm{~dB}\end{array}$ & $65^{\circ}$ & $57^{\circ}$ & $53^{\circ}$ & $51^{\circ}$ & $50^{\circ}$ \\
\hline & $\begin{array}{l}\text { Invariant latitude, night } \\
@ 6.6 \mathrm{MHz} 10 \mathrm{~dB}\end{array}$ & $65^{\circ}$ & $60^{\circ}$ & $56^{\circ}$ & $53^{\circ}$ & $53^{\circ}$ \\
\hline & Minimum duration [h] & 22 & 46 & 71 & 83 & 89 \\
\hline
\end{tabular}

\section{Variations of relativistic electron flux of the outer radiation belt}

The variations of the relativistic electron flux of the outer radiation belt are known to be correlated with the solar wind speed (e.g., Paulikas and Blake 1979; Li et al. 2011) and the southward component of the IMF (Miyoshi and
Kataoka 2008; Miyoshi et al. 2013). Flux variations are associated with magnetic storms, and their dependence on the solar wind structures such as CME and the corotating interaction region (CIR) has been observed (Miyoshi and Kataoka 2005, 2011). 
In order to investigate variations and the worst case, i.e., the largest flux enhancement, we analyzed the fluence of radiation belt electrons in geostationary orbit (GEO), while the occurrence probability of electron flux was estimated by, for example, Meredith et al. (2015) and Reeves et al. (2020). Using a long-term database of relativistic electrons with $\mathrm{E}>2 \mathrm{MeV}$ from 1998 to 2019 based on GOES-10, 11, and 15 in GEO, we derived the maximum fluence in each year. We conducted an extreme value analysis for these maximum fluences, and we derived fluxes of $0.6 \times 10^{10}$ and $3 \times 10^{10} / \mathrm{cm}^{2}$ str as onceper-year and once-per-10-year values, respectively. We also derived $10 \times 10^{10}$ and $26 \times 10^{10} / \mathrm{cm}^{2}$ str as once-per100-year and once-per-1000-year values, respectively. These values were derived from the extreme value analysis, and further investigations to identify how to realize such extreme conditions of the outer radiation belt by considering possible accelerations and loss processes are necessary.

\section{Geomagnetic storms}

Geomagnetic storms are large-scale magnetospheric disturbances caused by the injection of solar wind energy into the magnetosphere when the solar wind is accompanied by a southward magnetic field. Geomagnetic storms are characterized by a depression of the geomagnetic field at mid- and low latitudes for a few days, which is primarily caused by the development of a ring current. The Dst index is a commonly used measure of geomagnetic storms. Tsubouchi and Omura (2007) investigated the occurrence probability of intense geomagnetic storms by analyzing time series of the Dst index from 1957 to 2001. They utilized extreme value statistics to estimate the storm intensity $S_{\mathrm{T}}$ expected to occur within a period of $T$ years for a large event with a peak Dst $<-100 \mathrm{nT}$. The estimated value for $T \leq 10$ years was an overestimate of the actual observation, while the estimated value matched the actual measurement for longer periods. The calculated values were $S_{10}=450.8 \pm 26.7$ nT and $S_{100}=645.3 \pm 109.2$ nT. From Fig. 6 of Tsubouchi and Omura (2007), the Dst index of a once-per-1000-year geomagnetic storm is $-934 \mathrm{nT}$ with a $95 \%$ confidence interval from -320 to $-1520 \mathrm{nT}$.

Assuming that the magnetospheric internal pressure has an upper limit, Vasyliunas (2011) estimated the lower limit of the Dst index to be $-2500 \mathrm{nT}$ with the aid of the Dessler-Parker-Scopke relationship between the Dst index and the total energy of equatorial ring current particles. Therefore, the estimated value of Dst $=-934 \mathrm{nT}$ for the probability occurrence of once per 1000 years is plausible.

\section{Substorms}

A substorm is a disturbance accompanied by auroral breakups, the development of an auroral electrojet, and the deformation of the magnetospheric structure. We used the AL index, which represents the magnitude of the westward auroral jet current, as a measure of the magnitude of a substorm. The AL index is the lower envelope curve of the superimposed fluctuations of the horizontal geomagnetic component observed at several points just below an aurora zone. Nakamura et al. (2015) calculated the regression cycle of the AL index and estimated the AL index values corresponding to once per 10,100 , and 1000 years as $-4058,-4161$, and $-4190 \mathrm{nT}$, respectively. (The values are slightly different from the original paper.)

The aurora oval moves to lower latitudes when the geomagnetic activity increases. During the geomagnetic disturbed period, the AL index may underestimate the auroral electrojet because the geomagnetic data at a specific magnetic latitude are used to derive the AL index. To overcome this problem, the SuperMAG Electrojet (SME) index was proposed, in which the magnetic disturbances observed at many points are used (Newell and Gjerloev 2011). The lower envelope of this index is called the SML index and is widely used instead of the AL index. By power-law fitting of the cumulative occurrence distribution of the SML index for the period from 1980 to 2018, we estimated the SML index values corresponding to once per 10,100 , and 1000 years to be $-4000,-5000$, and $-5900 \mathrm{nT}$, respectively.

\section{lonospheric disturbances}

Irregular ionospheric variations are the result of a combination of disturbances propagated from the low atmosphere and solar-driven disturbances. The occurrence probability and duration vary among the ionospheric phenomena.

\section{Extreme total electron content (TEC)}

The ionospheric plasma delays the propagation of radio waves, which is one of the major factors causing satellite positioning errors. In readiness for hazardous ionospheric conditions, extreme TEC values with occurrences of once per year, 10 years, and 100 years in Japan were deduced using 22 years of Global Navigation Satellite System (GNSS) data and 62 years of F-layer critical frequency (foF2) data obtained by an ionosonde (Nishioka et al. 2021). By studying cumulative distribution functions of daily maximum TEC and foF2, they concluded that the once-per-year, once-per-10-year, and onceper-100-year TECs are about 90, 150, and 190 TECU (1 TECU $=1$ TEC unit $=10^{16} \mathrm{~m}^{-2}$ ) at Tokyo, respectively. 
Extreme TEC values were also estimated in southern and northern Japan in addition to those in Tokyo by Nishioka et al. (2021). Statistical analysis showed that TEC values in Kagoshima and Hokkaido, which are in southern and northern Japan are 1.2 and 0.8 times those in Tokyo, respectively. Therefore, the once-per-year, once-per-10-year, and once-per-100-year TECs were estimated to be about 110 (70), 160 (105), and 230 (150) TECU at Kagoshima (Hokkaido), respectively.

\section{Dellinger phenomenon}

Solar flares trigger an increase in plasma density up to the low-altitude ionosphere and cause the absorption of radio waves, especially in high-frequency (HF) ranges, which is called short-wave fadeout (SWF) or the Dellinger phenomenon. Tao et al. (2020) focused on the duration and absorption intensity to estimate extreme SWF events, as follows.

An empirical equation representing the degree of SWF in long-distance $\left(\sim 10^{5} \mathrm{~km}\right)$ short-wave circuits was proposed by Maeda and Inuki (1972). They obtained the relationship based on 11 SWFs commonly observed in three circuits in March-June 1970. Using a generalized empirical relationship for absorption obtained as a function of solar X-ray flux of 1-8 $\AA$ with reference to the extreme solar flare classes with occurrence probabilities of once per 1, 10, 100, and 1000 years (Sect. "Solar flares"), we estimated the absorption intensities at $6.6 \mathrm{MHz}$ used for civil aviation communications to be $71,83,93$, and $100 \mathrm{~dB}$, respectively.

The minimum reflection frequency, fmin, was used to detect SWFs from 15-min-resolution ionosonde observations at Kokubunji, Tokyo, from 1981 to 2016. The cumulative occurrence distribution of SWF duration was fitted by a function using the 616 detected SWFs. The durations of extreme events with occurrence probabilities of once per 10,100, and 1000 years were estimated to be 3.6 , 6.8 , and $11.9 \mathrm{~h}$, respectively.

The extreme SWF cases with occurrence probabilities of once per 10, 100, and 1000 years were extrapolated from the limited observation period. The degree of ionization of the upper atmosphere is usually on the order of $10^{-6}$, so increasing the solar X-ray flux by $10-100$ times would place it in the range where similar ionization processes are expected. The SWF duration is mainly determined by the solar flare duration. The correlation between the solar flare duration and the flare ribbon area has been reported by several research groups (e.g., Reep and Knizhnik 2019). Assuming the flare ribbon area is equal to the maximum size of solar spots in observational records as described in Sect. "Solar flares", the solar flare duration becomes $\sim 1$ day from the empirical relationship. This duration is considerably longer than the SWF duration of up to about $12 \mathrm{~h}$ proposed here. Since SWFs occur only during the daytime, their duration depends on the timing of the event initiation. For mid-latitude regions such as Japan, the longest duration is about $12 \mathrm{~h}$ (Tao et al. 2020).

\section{Polar cap absorption (PCA)}

Ionization at low altitudes caused by SEP precipitation into the polar region causes the absorption of radio emission especially in HF ranges. This phenomenon is called PCA. We define the PCA event size by its latitudinal extension and duration.

Here, we refer to the SEP energy spectra categorized by once-per- $x$-year occurrence probabilities by Jiggens et al. (2018) and the estimation method for the latitudinal extension and absorption intensity of PCA proposed by Sauer and Wilkinson (2008). A Kp index of 4, 7, 8, and 9 is assumed for daily, once-per-year, once-per-10-year, and once-per-100-year events, respectively, for simplicity, although a magnetospheric storm is not necessarily related to SEP. The latitudinal extension of the $10 \mathrm{~dB}$ absorption region of a signal at $6.6 \mathrm{MHz}$ frequency used by civil aviation was estimated to be invariant magnetic latitudes of $53^{\circ}\left(56^{\circ}\right), 51^{\circ}\left(53^{\circ}\right)$, and $50^{\circ}\left(53^{\circ}\right)$ for daytime (nighttime) for once-per-10-year, once-per-100-year, and once-per-1000-year cases, respectively. From the duration of SEP based on past observations (Sauer and Wilkinson 2008), the PCA duration was estimated to be 22-89 h. Since lower-frequency signals undergo greater absorption, their duration is longer for a given absorption intensity.

\section{Sporadic E-layer (Es layer)}

The Es layer is a thin layer with high electron density, which appears suddenly and locally at an altitude of about $100 \mathrm{~km}$. Vertical neutral wind shear in the lower thermosphere is considered to play an important role in the formation of this layer. When the Es layer is highly developed, radio waves of VHF bands, which are not usually reflected by the ionosphere, are reflected and abnormally propagated, resulting in interference of distant broadcasting stations. The critical frequency of the E-region (foEs) obtained with ionosonde observation is a proxy of the Es layer. The duration of the Es layer is also an important parameter for users of radio waves.

Here, we conducted a statistical study of foEs observed by an ionosonde at Tokyo from 1957 to 2018 in order to determine the maximum usable frequency (MUF) for the propagation of great-circle distances of 1000 and $2000 \mathrm{~km}$. The propagation of a great-circle distance of $1000 \mathrm{~km}(2000 \mathrm{~km})$ over Tokyo means that radio waves originating from a point $500 \mathrm{~km}(1000 \mathrm{~km})$ away from Tokyo are obliquely reflected by the Es layer and reach 
a point $500 \mathrm{~km}(1000 \mathrm{~km})$ away in the opposite direction. For the estimation of MUF from foEs, a modified secant law with factors of 4.4 and 6.0 was used for the great-circle distances of 1000 and $2000 \mathrm{~km}$, respectively (e.g., Davies 1990). The cumulative distribution function of MUF, which was converted from the daily maximum foEs using the modified secant law, showed that MUFs for great-circle distances of $1000 \mathrm{~km}$ and $2000 \mathrm{~km}$ can be 100 (130), 110 (>180), and $>130(>180) \mathrm{MHz}$ for the occurrence probabilities of once per year, 10 years, and 100 years, respectively. The inequality sign before 130 and 180 indicates that the propagation at an MUF of more than $130 \mathrm{MHz}(180 \mathrm{MHz})$ over the great-circle distance of $1000 \mathrm{~km}(2000 \mathrm{~km})$ is no longer valid since the upper limit of the ionosonde observation is $30 \mathrm{MHz}$.

The duration of abnormal propagation at $80 \mathrm{MHz}$, which is widely used for frequency modulation (FM) radio, was investigated using the ionosonde observations in Tokyo from 1957 to 2018. According to the modified secant law, the frequency at which an $80 \mathrm{MHz}$ radio wave propagates for a great-circle distance of more than $1000 \mathrm{~km}(2000 \mathrm{~km})$ is more than $18 \mathrm{MHz}(13.3 \mathrm{MHz})$. The longest durations of $18 \mathrm{MHz}$ (1000 km propagation) and $13.3 \mathrm{MHz}(2000 \mathrm{~km})$ waves are 3 and $5 \mathrm{~h}$, respectively, which correspond to an occurrence probability of about once per 10 years.

The occurrence frequency of abnormal propagation shown here is lower than that reported by Sakai et al. (2019), who investigated the long-distance abnormal propagation of VHF radio waves for air navigation (108-118 MHz). The occurrence frequency and its duration studied here are for propagation from one point to another point. In practice, it is necessary to consider the number of transmitting stations in all directions and the size of the Es layer that becomes a reflector.

\section{Plasma bubbles}

Plasma bubbles are an irregular and extremely low density regions generated in the equatorial and low-latitude ionosphere caused by the Rayleigh-Taylor instability. Plasma bubbles affect radio wave propagation from satellites to the ground. Plasma irregularities inside plasma bubbles cause rapid fluctuation in satellite signal intensity, which is called scintillation, to make signal tracking difficult. The difference in plasma density between inside and outside plasma bubbles affects differential GNSS correction. It is important to understand the occurrence frequency of plasma bubbles and their duration. Here, using GNSS-TEC data, an index for plasma bubbles was statistically studied at Okinawa, where plasma bubbles are often observed.

To detect plasma bubbles, the rate of TEC change index (ROTI) has been used in previous studies. ROTI is the standard deviation of the time derivative of the TEC over 5 min. We calculated ROTI using GPS Earth Observation NETwork(GEONET) GNSS-TEC data at Okinawa. To omit ROTI enhancement caused by traveling ionospheric disturbances (TIDs), which are often observed in the mid-latitude ionosphere, plasma bubble generation was considered to occur when ROTI exceeds the threshold value at Okinawa but not the threshold value at Tokyo. The threshold was determined to be 0.3 TECU/min by trial and error. The result shows that the monthly occurrence probability exceeds $40 \%$ during a high solar activity period, while no plasma bubbles were detected $(0 \%)$ in a low solar activity period (e.g., the PSTEP report). The cumulative frequency distribution of the duration of plasma bubbles that appeared in Okinawa during 22 years from 1997 to 2018 was obtained. From this, it was found that the duration of a plasma bubble was $4-5 \mathrm{~h}$ about once per year, and $6 \mathrm{~h}$ about once per 10 years.

\section{Estimation of effect of space weather on society}

Table 2 is a matrix summarizing the effect of space weather on Japanese society, evaluated from the following discussions. We evaluate effects into three categories: (i) negligible effects, (ii) those requiring adequate measures such as aircraft route changes and/or other alternative backup methods, and (iii) those preventing continuous operations, e.g., suspension of aircraft operation. These three categories are shown in green, yellow, and red, respectively, in Table 2. Note that our estimations might be modified by future research and data, with those most likely to be modified shown by asterisks $\left(^{*}\right)$ in the table. Note also that cases where effects depend on system details, especially for radio communication and positioning usage, are marked by filled squares (black square). We evaluated and classified the effects conservatively, explaining definitions as much as possible in the following sections.

\section{Electricity}

It is known that GIC due to a giant magnetic storm causes an overcurrent flowing through a transmission line. There is a risk of damage to the power grid, resulting in a stagnant power supply and a decrease in the output of industries that use power.

In March 1989, GIC induced by a large-scale magnetic storm caused a failure of the power transmission system due to the unnecessary operation of protection relays, causing a blackout for $\sim 9 \mathrm{~h}$ around Quebec, Canada, affecting about 6 million people. On October 30, 2003, a transformer in South Africa was burned by overheating near its iron core, which was attributed to GIC. GIC has also been observed in Japan. Attributed to a magnetic 
storm that occurred on November 6, 2001, GIC of up to 42 A was reported at the Sun-en substation (Tabata and Ogawa 2003). Strong GIC with a peak value of 129.09 A was observed during the magnetic storm that occurred during the Halloween event on October 31, 2003. In this event, GIC exceeding 50, 75, and 100 A continued for 9, 5 , and $2 \mathrm{~min}$, respectively. No anomalies of a transformer were found for this GIC (The Institute of Applied Energy 2015).

Nakamura et al. (2018) developed a model for estimating GIC generated in a high-voltage power grid taking into account Japan's complicated geography and underground structure. On the basis of this model, the characteristics of the GIC phenomenon in Japan are summarized as follows: (i) the geomagnetic induced electric field is strengthened near the coast, such as the Tohoku Sanriku coast. (ii) Electric charge is accumulated in bays and the electric field is distorted by the underground structure, e.g., in the region from Hokkaido Ishikari Bay to northwestern Hokkaido and in the region from Tokyo Bay to Sagami Bay as shown in Fig. 3 of Nakamura et al. (2018). (iii) The sea depth greatly affects the strength of the electric field, as shown in their Fig. 4. Calculating the GIC while changing the direction of the geomagnetic induced electric field from east to south (their Fig. 5) showed that (iv) GIC tends to be strengthened near the coastline, (v) GIC is concentrated and strengthened at end points of the power grid, and (vi) GIC is also strengthened in areas where transmission lines are dense. The strength of the induced electric field changes markedly with the situation of the geomagnetic storm, i.e., the direction of current flow, due to the complicated geography and underground structure. Therefore, to estimate the effect of GIC in Japan more accurately, it is necessary to describe the ionospheric and magnetospheric currents, which are the inputs of the model of Nakamura et al. (2018), with high accuracy.

The scale for extreme GIC was examined on the basis of the findings obtained so far. Kappenman (2004) analyzed GIC measured at Chubu Electric Power and found a linear relationship between GIC strength and the Dst index. Furthermore, according to an extrapolation by a linear approximation, the GIC for an event with Dst $=-1700$ $\mathrm{nT}$, estimated for the 1859 event, is three times as strong as that for the magnetic storm in March 1989 (Kappenman 2004). From the definition of the magnetic storm scale discussed in Sect. "Geomagnetic storms" and Table 1 combined with the GIC scale reported by Kappenman (2004), the GICs that occur once per 100 and 1000 years are about 93 and $136 \mathrm{~A}$, respectively. We consider that the effect of GICs of up to once-per-100 year events on Japan society is negligible (green in Table 2), while that of once-per-1000-year GIC might require adequate measures (yellow), although the estimation includes uncertainty.

\section{Satellite operations}

Multiple types of satellite anomalies are caused by (i) SEPs, (ii) radiation belt electrons with energy of several $\mathrm{MeV}$, and (iii) the injection of substorm high-temperature electrons (from several to several tens of $\mathrm{keV}$ ) from the magnetotail to the near-Earth region due to a magnetospheric substorm.

The risk of surface charging/discharging in a plasma environment around a satellite increases with the activity of the magnetosphere associated with the substorm. This risk is considered to be increased during the phase of declining solar activity (e.g., Matéo-Vélez et al. 2018; Reeves et al. 2020). However, the surface charging/discharging risk of geostationary/polar orbit satellites is not simply correlated with the increase in the activity of the magnetosphere, which makes the impact assessment difficult (Table 3 in Sect "Required research topics"). Also, the risk of surface charging/discharging depends on the structure and materials of the individual satellite.

The radiation belt electrons cause internal charging/ discharging of satellites such as GPS in medium Earth orbit (MEO) and meteorological/communication satellites in GEO, so the radiation belt electrons are potentially serious hazards causing satellite malfunctions and anomalies. The risk of internal charging qualitatively increases with the electron flux of the outer radiation belt, while it also depends strongly on the materials and design of each satellite, and it is difficult to define the occurrence probability of an anomaly for an individual satellite. According to the statistical analysis of past satellite anomalies, such a satellite anomaly occurs about once per year.

A single event upset is a malfunction or failure of a semiconductor logic circuit due to energetic charged particles such as protons and heavy ions from a solar flare, which could cause disturbances in satellite attitude via an abnormality in a sensor controlling the satellite attitude. Single event upsets occur frequently above the South Atlantic Anomaly (SAA) belt, into which high-energy particles frequently precipitate; $75 \%$ of all such events occur above the SAA belt (Kamide 2011). These events also often occur during large solar flares and large proton flux (>10 MeV) events.

In addition, space weather causes the deterioration of solar cells, the disturbance of orbit and attitude due to atmospheric drag, and failure in space communications. Enhanced atmospheric drag is associated with atmospheric expansion due to atmospheric heating, which is driven by solar emission enhancement with solar flares and the development of electric and current systems with 
Table 2 Matrix representing effects of space weather on society

\begin{tabular}{|c|c|c|c|c|c|c|c|}
\hline \multirow[b]{2}{*}{ Field } & \multirow[b]{2}{*}{$\begin{array}{l}\text { Effect and } \\
\text { hazard }\end{array}$} & \multirow[b]{2}{*}{$\begin{array}{l}\text { Causal space } \\
\text { weather } \\
\text { phenomena }\end{array}$} & \multicolumn{5}{|c|}{ Occurrence probability and effect } \\
\hline & & & $\begin{array}{l}\text { Daily } \\
\text {-several } \\
\text { per year }\end{array}$ & $\begin{array}{l}\text { Once } \\
\text { per } \\
\text { year }\end{array}$ & $\begin{array}{l}\text { Once per } 10 \\
\text { years }\end{array}$ & $\begin{array}{l}\text { Once per } \\
100 \text { years }\end{array}$ & $\begin{array}{l}\text { Once per } \\
1000 \\
\text { years }\end{array}$ \\
\hline Electricity & $\begin{array}{l}\text { Black out } \\
\text { (Overcurrent } \\
\text { in power } \\
\text { lines) } \\
\end{array}$ & $\begin{array}{l}\text { Geomagnetically } \\
\text { induced current } \\
\text { (GIC) }\end{array}$ & & & & & * \\
\hline \multirow{2}{*}{$\begin{array}{l}\text { Satellite } \\
\text { operation }\end{array}$} & $\begin{array}{l}\text { Spacecraft } \\
\text { surface } \\
\text { charging } \\
\end{array}$ & Substorm electron & & & & * & $*$ \\
\hline & $\begin{array}{l}\text { Spacecraft } \\
\text { internal } \\
\text { charging }\end{array}$ & Energetic electron & & & & $*$ & $*$ \\
\hline \multirow{6}{*}{$\begin{array}{l}\text { Radio } \\
\text { communic } \\
\text { ation and } \\
\text { broadcasti } \\
\text { ng }\end{array}$} & \multirow{4}{*}{$\begin{array}{l}\text { High } \\
\text { frequency } \\
\text { (HF) hazard }\end{array}$} & $\begin{array}{l}\text { Ionosphere } \\
\text { negative storm }\end{array}$ & & & & * & $*$ \\
\hline & & $\begin{array}{l}\text { Dellinger } \\
\text { phenomenon }\end{array}$ & & & & * & $*$ \\
\hline & & $\begin{array}{l}\text { Polar cap } \\
\text { absorption (PCA) }\end{array}$ & & & & * & $*$ \\
\hline & & Plasma bubble & & & & $*$ & $*$ \\
\hline & \multirow{2}{*}{$\begin{array}{l}\text { Very high } \\
\text { frequency } \\
\text { (VHF) hazard }\end{array}$} & Sporadic E-layer & $\triangle$ & $\triangle$ & $\triangle$ & $\triangle$ & $\triangle$ \\
\hline & & Plasma bubble & & & & * & $*$ \\
\hline \multirow{3}{*}{$\begin{array}{l}\text { Positionin } \\
\text { g }\end{array}$} & \multirow{3}{*}{$\begin{array}{l}\text { Poor } \\
\text { positioning } \\
\text { accuracy }\end{array}$} & $\begin{array}{l}\text { Ionospheric } \\
\text { positive storm }\end{array}$ & & & & * & $*$ \\
\hline & & Plasma bubble & & & & * & * \\
\hline & & $\begin{array}{l}\text { Fast propagation of } \\
\text { TEC structure in } \\
\text { auroral region }\end{array}$ & & & & $*$ & $*$ \\
\hline $\begin{array}{l}\text { Human } \\
\text { space } \\
\text { activity }\end{array}$ & $\begin{array}{l}\text { Astronaut } \\
\text { exposure }\end{array}$ & $\begin{array}{l}\text { Solar energetic } \\
\text { particles (SEPs) }\end{array}$ & & & & & $*$ \\
\hline $\begin{array}{l}\text { Daily life } \\
\text { on the } \\
\text { Earth's } \\
\text { surface }\end{array}$ & $\begin{array}{l}\text { Exposure on } \\
\text { the ground }\end{array}$ & $\begin{array}{l}\text { Solar energetic } \\
\text { particles (SEPs) }\end{array}$ & & & & & $*$ \\
\hline \multirow{9}{*}{ Aviation } & \multirow{5}{*}{$\begin{array}{l}\text { Communicati } \\
\text { on failure }\end{array}$} & $\begin{array}{l}\text { Ionospheric } \\
\text { negative storm }\end{array}$ & & & & $*$ & $*$ \\
\hline & & $\begin{array}{l}\text { Dellinger } \\
\text { phenomenon }\end{array}$ & & & & $*$ & $*$ \\
\hline & & $\begin{array}{l}\text { Polar cap } \\
\text { absorption (PCA) }\end{array}$ & & & & $*$ & $*$ \\
\hline & & Plasma bubble & & & * & * & $*$ \\
\hline & & Sporadic E-layer & & & * & * & $*$ \\
\hline & \multirow{3}{*}{$\begin{array}{l}\text { Poor } \\
\text { positioning } \\
\text { accuracy }\end{array}$} & $\begin{array}{l}\text { Ionospheric } \\
\text { positive storm }\end{array}$ & $*$ & $*$ & $*$ & $*$ & $*$ \\
\hline & & Plasma bubble & $*$ & $*$ & * & $*$ & $*$ \\
\hline & & $\begin{array}{l}\text { Fast propagation of } \\
\text { TEC structure in } \\
\text { auroral region }\end{array}$ & $*$ & $*$ & $*$ & $*$ & $*$ \\
\hline & $\begin{array}{l}\text { Aircrew } \\
\text { exposure }\end{array}$ & $\begin{array}{l}\text { Solar energetic } \\
\text { particles (SEPs) }\end{array}$ & & & & & $*$ \\
\hline
\end{tabular}

Color scale

\begin{tabular}{|c|c|c|}
\hline $\begin{array}{c}\text { Effects are } \\
\text { negligible }\end{array}$ & $\begin{array}{c}\text { Effects require adequate } \\
\text { measures, e.g., back up } \\
\text { preparation }\end{array}$ & $\begin{array}{c}\text { Events prevent continuous } \\
\text { operations and problems have long } \\
\text { duration }\end{array}$ \\
\hline
\end{tabular}


Table 2 (continued)

Levels of effects are distinguished by colors, as indicated in the color table, with cases for which there has been insufficient evaluation so far shown in white; see text for details

indicates cases where the effect depends on the system, ${ }^{*}$ indicates cases where the result may change as a result of further analysis, and $\triangle$ denotes cases where phenomena are "different from normal" rather than system damage. Note that "Aviation operation" contains several components such as communication, positioning, and exposure

increased auroral precipitation during magnetic storms. Accurate evaluations of atmospheric heating due to solar flares and magnetic storms and their effects on satellite orbit and attitude are required for the quantitative evaluation of the effect of atmospheric drag on satellite operation.

\section{Radio communication and broadcasting}

The ionosphere continually varies under the influence of the Sun and the lower atmosphere. The ionospheric plasma density and structure affect the reflection and absorption of radio waves in the mid- and short-wave bands, communication and positioning using satellites, and delays and fluctuations of radio waves in the UHF band. Therefore, space weather phenomena in the ionosphere can affect short-wave HF communication/broadcasting used for aviation (Sect. "Aviation operation"), VHF communication/broadcasting used for disaster prevention and firefighting radio, and UHF communications used in satellite communications. As mentioned above, effects depend on the system details and usages.

Although the role of HF communication/broadcasting is limited owing to its existing use by communication satellites and submarine cables, it is continuously used for aviation radio, ship radio, disaster radio, and long-distance communication such as international radio broadcasting. The ionospheric phenomena that affect HF communication are ionospheric negative storms, the Dellinger phenomenon, PCA, and plasma bubbles.

Ionospheric negative storms are an unusual decrease in plasma density. As they are mostly associated with geomagnetic storms, their occurrence is anticipated in periods of medium and high solar activity. During the former, foF 2 is typically about $2-8 \mathrm{MHz}$. If a moderate event (once per year) with $~ 30 \%$ plasma decrease occurs during nighttime (daytime), the corresponding MUF for a great-circle distance of $2000 \mathrm{~km}$ will typically decrease from about 12-48 to 8.4-34 MHz. If a severe event (once per 10 years) with $50 \%$ plasma decrease occurs, the MUF will decrease from 12-48 to 6-24 MHz. Part (most) of the HF communication frequency range, up to $30 \mathrm{MHz}$, is affected by moderate (severe) events, as labeled in yellow (red) in Table 2.

The Dellinger phenomenon occurs with solar flares, and PCA is mainly due to SEPs from the Sun. The magnitude and frequency of these phenomena largely vary with the 11-year solar activity cycle. The occurrence frequency of plasma bubbles also increases with the solar activity (Sect. "Plasma bubbles"). However, plasma bubbles have little effect on preventing HF radio communication and broadcasting. Therefore, communication and broadcasting using HF basically depend on the solar activity cycle of 11 years. We found that ionospheric phenomena of the scale from daily to once per year (Table 1 ) have little effect during periods of low solar activity and that the effect, except for that of plasma bubbles, becomes significant for large-scale phenomena that occur less frequently than once per 10 years, as labeled in red in Table 2.

Since radio waves in the VHF band are not normally reflected in the ionosphere, they are used for FM radio broadcasting, air traffic control, disaster prevention/firefighting radio within sight distance, and so on. The ionospheric phenomena that affect VHF communication and broadcasting are the Es layer and plasma bubbles.

In the Es layer, which is a layer with a high electron density that appears suddenly and locally at an altitude of about $100 \mathrm{~km}$, VHF radio waves, which are normally not reflected in the ionosphere, are reflected and propagated abnormally. This may interfere with communication and broadcasting outside the sight distance. The Es layer is not closely related to solar activity, and in Japan, it has high seasonal dependence, such as high occurrence in summer. Therefore, we label the Es layer in yellow with triangles for all event scales, indicating a different situation from normal rather than a phenomenon causing system damage.

VHF band radio waves are scattered by the irregular structure of the plasma in plasma bubbles and/or propagate along the structure of plasma bubbles. Some of them may abnormally propagate outside the sight distance. The radio wave intensity of anomalous propagation in the VHF band caused by plasma bubbles is smaller than that of the sight distance and that of anomalous propagation reflected by the Es layer. On the other hand, VHF used in satellite communication is also strongly affected by plasma bubbles via scintillation as UHF described in the next paragraph. Therefore, we label this case in green, yellow, and red for daily, once-per-year, and once per $\geq 10$ year events, respectively.

UHF radio waves used in satellite communication usually pass through the ionosphere. Short-period fluctuations are seen in the received signal intensity due to the 
irregular structure of plasma associated with plasma bubbles and so on. This phenomenon is called "ionospheric scintillation" or simply "scintillation", and it leads to the deterioration of communication quality between the ground and satellites and the disturbance of image data transmitted from satellites. This phenomenon has been known for a long time and affects satellite communications such as Inmarsat in Japan (Karasawa et al. 1985). In addition, during the US Army's al-Qaeda sweeping operation "Operation Anaconda" in Afghanistan in March 2002, the UHF satellite communication (SATCOM) failure caused fatalities among US troops. It has been pointed out that a plasma bubble may have caused the failure (Kelly et al. 2014). The higher the frequency, the smaller the effect of ionospheric scintillation. It is almost negligible in satellite communication systems with frequencies above $10 \mathrm{GHz}$ compared with other effects such as the troposphere. On the other hand, in satellite communication systems of the L-band at $1.5 \mathrm{GHz}$ and the $\mathrm{S}$ band at $2 \mathrm{GHz}$, the effect of scintillation due to plasma bubbles cannot be ignored. The longer the radio wave propagation path through the plasma bubble, which usually extends in the north-south direction along the magnetic field line, the greater the effect becomes. Therefore, in Japan, it is considered that communication with GEO satellites and other low-elevation-angle satellites could be greatly affected by plasma bubbles (Karasawa et al. 1985).

\section{Positioning usage}

Positioning with GPS satellites (GNSS) determines the position using radio waves coming from multiple satellites. Radio waves of two frequencies in the L1 and L2 bands are transmitted from GPS satellites, and singlefrequency positioning using only one frequency in the L1 band and dual-frequency positioning using both radio waves are both possible. Since the delay of the phase velocity of radio waves due to the ionosphere depends on their frequency, dual-frequency positioning has the advantage of eliminating errors due to the ionosphere. On the other hand, since the equipment is expensive, most of the positioning is performed by single-frequency positioning.

Space weather phenomena that cause the deterioration of single-frequency positioning accuracy are ionospheric positive storms and ionospheric scintillation due to plasma bubbles. An ionospheric positive storm is an unusual ionospheric plasma density enhancement, which is often driven by magnetospheric storms and/or low-altitude atmospheric activities. The increase in the ionospheric delay corresponding to the TEC due to ionospheric positive storms increases the error in a modelbased correction. In the case of a differential positioning system, the correction error increases when it exceeds the maximum value that can be corrected. The vertical TEC maximum value of 70-110 TECU for ionospheric positive storms (Sect. "Extreme total electron content (TEC)" and Table 1) that occur about once per year corresponds to a delay of 11-18 $\mathrm{m}$ at the GPS L1 frequency. Ionospheric positive storms of 105-160 TECU, which occur about once per 10 years, have a delay of $17-26 \mathrm{~m}$, and those of 150-230 TECU, which occur once per 100 years, have a delay of $24-37 \mathrm{~m}$. The slant delay along the line of sight of a satellite can be 2-3 times more than the vertical delay depending on the satellite elevation angle. The slant delay is translated into a position error depending on the geometry of the satellites used for positioning. This translation is represented by the dilution of precision (DOP) factor which is on the order of 1 under an open-sky condition. Even though broadcast ionosphere corrections based on an empirical ionosphere model are available for a GNSS signal, the error can be as large as 50\% (Klobuchar 1987). Thus, a vertical delay could result in position error values similar to the vertical delay. Let us consider a GNSS user on the ground. A $10 \mathrm{~m}$ error in position is within the typical size of a building/road and of little concern (green), while a $\sim 20 \mathrm{~m}$ uncertainty alters the location, possibly to the other side of a road, meaning that care is required (yellow), and positioning with $\sim 30 \mathrm{~m}$ error cannot be reliably used alone without human visual judgement (red).

Plasma bubbles have two effects: spatial variation of the ionospheric delay and ionospheric amplitude scintillation. There is a possibility that the positioning accuracy will deteriorate during the period when a plasma bubble is generated. The duration of plasma bubbles (Table 1) is estimated to be $4 \mathrm{~h}$ or longer for once-per-year events. Since our analysis uses the ROTI index, which is sensitive to larger structures than those affecting scintillation, the duration of scintillation should be somewhat shorter than our estimated duration. On the other hand, the extent of the deterioration of positioning accuracy cannot generally be given since it depends on the positioning system. The effect of plasma bubbles becomes more serious when their occurrence frequency increases with solar activity and when phenomena occur with a longer duration. Thus, plasma bubbles with daily occurrence, once-peryear occurrence, and once per $\geq 10$ year occurrence are, respectively, labeled in green, yellow, and red in Table 2.

At high latitudes, localized TEC structures moving with a high-speed auroral jet could cause radio phase scintillation. In Hokkaido, the northern part of Japan, the detection of a diffuse red aurora is reported infrequently, about once per 10 years. This diffuse red aurora is the upper part of the aurora located at higher latitudes. Therefore, their scintillation effect on Japan is defined as negligible (green) for once per 10 years, while the effect 
of larger-scale events associated with the aurora extending over Japan is unknown and not defined (white) here. The definition of the event size for these scintillation required for practical usage is an important future work.

In dual-frequency positioning, the error due to the ionospheric delay can be estimated and almost eliminated by receiving and calculating the radio waves of two different frequencies from one GPS satellite at the same time. However, when a loss of locking occurs, i.e., the GNSS receiver no longer tracks the signal accurately, owing to the irregular structure of the ionospheric electron density due to plasma bubbles or ionospheric scintillation, the number of satellites that can be used for positioning decreases, leading to a decrease in positioning accuracy. It is necessary to be able to use signals of two frequencies together for dual-frequency positioning. If the GPS $\mathrm{L} 2 \mathrm{P}(\mathrm{Y})$ signal, whose tracking ability is weaker than that of the L1 C/A signal, is used as the second frequency in dual-frequency positioning, the performance could be less than that of single-frequency positioning.

\section{Aviation operation}

In the aviation field, important factors that could be affected by space weather are communication, positioning, and the exposure dose of crew members. Note that redundant measures are included for communication and positioning in aviation for safety. For example, one space weather phenomenon might result in the loss of one of the measures, e.g., HF communication, while other methods, e.g., SATCOM, may be usable as a back-up. Therefore, we label the failure of each measure in yellow in Table 2 because back-up methods are required from the viewpoint of aircraft operation. If multiple phenomena occur simultaneously, however, the suspension of flights might be required, i.e., the "red" level, but this combined loss of measures is not considered in detail hereafter and the examination of such cases is future work.

Since November 2019, space weather information has additionally been provided to civil aviation authorities. International Civil Aviation Organization (ICAO) determines thresholds representing alert levels called "moderate" and "severe" conditions for several space weather phenomena. Some of them are referred to in the following discussion.

\section{Aviation: radio communication}

Aircraft use SATCOM and short-wave HF band communication with ionospheric reflection, and domestic flights use short-range VHF band communication. Shortwave communication is used in offshore control outside the range of VHF radio waves and in polar regions where SATCOM functionality is poor. Short-wave HF communication is frequently influenced by space weather phenomena, such as the ionospheric negative storm, Dellinger phenomenon, PCA, and plasma bubble. The Es layer affects VHF communication.

Ionospheric negative storms decrease the maximum usable frequency (MUF) of HF communication. A moderate (severe) level threshold of a 30\% (50\%) decrease in foF2 compared with the 30-day average of MUF is defined for ICAO space weather information. Statistical analysis by Nishioka et al. (2017) showed that moderate and severe thresholds can occur several times per year and once per year, respectively. The oceanic HF communication system covers the frequency range from 2 to $22 \mathrm{MHz}$. According to the discussion in Sect. "Radio communication and broadcasting", the use of frequencies in this band would be limited by ionospheric negative storms, but not all the frequencies would be unusable. It should be noted that lower frequency bands are generally noisier than higher frequency bands and may make HF communication unusable even if the MUF is higher than the lowest assigned frequency. Therefore, all events above once-per-year scale are labeled in yellow in Table 2.

For the Dellinger phenomenon, the evaluated durations of complete blackout are $>30 \mathrm{~min}, 2 \mathrm{~h}, 4 \mathrm{~h}$, and more than $7 \mathrm{~h}$ for the once-per-year, once-per-10-year, onceper-100-year, and once-per-1000-year events, respectively (Table 1). For aviation surveillance, a position report is required at least once per $30 \mathrm{~min}$ or $1 \mathrm{~h}$ in an oceanic flight. If the Dellinger phenomenon occurs, HF communication is not available and alternative methods are required; thus, it is labeled in yellow in Table 2 for once-per-year and larger events.

As described in Sect. "Polar cap absorption (PCA)", PCA extends to a lower latitude for a larger event size. An extension of $10 \mathrm{~dB}$ PCA up to the invariant magnetic latitude of $57^{\circ}\left(60^{\circ}\right)$ for daytime (nighttime), corresponding to a once-per-10-year case (Table 1), would affect flights, e.g., between Japan and New York and between Japan and northern Europe. Aviation routes have been changed to avoid PCA in at least four SEP events over two solar cycles. Therefore, we label onceper-year and larger events in yellow.

L-band data transmission via the space-based automatic dependent surveillance-broadcast (ADS-B) is also used for aviation surveillance in oceanic flights. Plasma bubbles can disturb such L-band data transmission, which could continue more than four hours for a larger than one-per-year event, necessitating the use of other communication methods (yellow).

The general effect of the sporadic E-layer is described in Sect. "Radio communication and broadcasting", while there is little effect for radio signals in the VHF aeronautical band from 108 to $137 \mathrm{MHz}$. Daily events have little effect. However, the anomalous 
propagation of radio waves in the frequency band with a signal level high enough to cause potential interference has been observed, which is now under investigation. Therefore, the green label assigned to the effect of the sporadic E-layer on aviation could be changed in the near future.

\section{Aviation: positioning/navigation}

The use of GNSS for positioning in aviation has been increasing. Wide area navigation (RNAV), which uses radio waves including GNSS, enables shorter aviation routes than those determined by previous navigation methods. Therefore, the installation of RNAV is being promoted and its use is expanding. Code positioning, one type of single-frequency positioning using a pseudo-range, is used in aviation navigation. The effect of the ionospheric delay is large in single-frequency positioning. Ionospheric disturbances such as ionospheric positive storms and plasma bubbles increase range-finding errors and degrade positioning accuracy. In addition, ionospheric scintillation reduces the number of usable satellites and the positioning accuracy. An augmentation system corrects the deterioration of accuracy and provides reinforcement information including integrity information to ensure safety even in rarely occurring worst cases. On the other hand, the augmentation system corrects the ionospheric delay using the data at GPS reference stations, so the local gradient of the ionospheric delay causes an additional error.

However, the evaluation of these effects on aviation positioning is very difficult, because the required performance of navigation systems depends on the flight phase and the architecture and design of the specific navigation system. Therefore, the impacts on aeronautical navigation are left unlabeled (white) in Table 2.

\section{Aviation: exposure dose of crew members}

When galactic cosmic rays (GCRs) or high-energy SEPs are incident on the atmosphere, they induce an air-shower by producing various secondary particles such as neutrons. Aircrews and passengers are exposed to an enhanced radiation dose due to these secondary particles. The GCR dose rate depends on the solar modulation potential, and it gradually varies with an approximately 11-year period. In contrast, the SEP dose rate suddenly increases when a large solar particle event occurs, and SEPs can be a potential hazard to aircrews and passengers.

An extensive air-shower generated by SEPs occasionally induces GLE. The detection of GLE can be used as an alert warning aircrews of exposure to SEPs.
However, the occurrence of GLE does not always result in a significant increase in the radiation dose at flight altitudes. As mentioned earlier, the frequency of occurrence of GLE is approximately once per year, and its magnitude is scaled by the event-integrated intensity (EII; Asvestari et al. 2017). For example, the EII of GLE 69, which is so far the largest event occurring in the twenty-first century, is $385 \%$ "h.

Using the Warning System for AVIation Exposure to SEPs (WASAVIES), we estimated the cumulative SEP dose during GLE 69 at a conventional flight altitude $(12 \mathrm{~km})$ to be at most $260 \mu \mathrm{Sv}$ (Sato et al. 2018a). Considering that the annual dose limitation for the public recommended by the International Commission on Radiological Protection (ICRP) is $1 \mathrm{mSv}$ (ICRP 2007), it is reasonable to assume that GLE with EII greater than that of GLE 69 requires action to reduce the SEP dose. The frequency of occurrence of such a significant GLE is approximately once per 10 years (Sect. "Solar energetic particles" and Table 1).

GLE 5, which occurred in February 1956, was the largest GLE since the observation by neutron monitors started in the 1940s. The EII of GLE 5 was $5202 \%$ h, and the maximum SEP dose for a certain flight route during GLE 5 was estimated to be $4.5 \mathrm{mSv}$ (Lantos and Fuller 2003). However, this SEP dose can be reduced to $1 \mathrm{mSv}$ by taking appropriate action such as changing the flight altitude and route. Thus, the cancellation of flights might not be necessary if a similar-scale GLE occurs in the future, although there is no international standard or recommendation for the cancellation policy due to SEP exposure. Under these considerations, the cancellation of flights is only necessary when a once-per-1000-year event occurs (Sect. "Solar energetic particles" and Table 1), such as that in AD 774/5 (Miyake et al. 2012). The fluence of SEPs during a historically large event was estimated to be 119-141 times higher than that during GLE 69 (Mekhaldi et al. 2015), during which the cumulative SEP dose for a certain flight would exceed $30 \mathrm{mSv}$.

\section{Human space activity}

Astronauts are also exposed to an enhanced radiation dose due to cosmic-ray exposure, which was estimated to be approximately $0.5 \mathrm{mSv} /$ day in the International Space Station (ISS) during the solar quiet period (Sato et al. 2018b). The radiation doses of astronauts are controlled by each space agency in order to surpress the values to below their career limits, i.e., 0.6-1.2 Sv (McKenna-Lawlor 2014). For example, astronauts must stay at rather well-shielded locations, e.g., the Russian module in ISS, during large solar particle events. 
If a male astronaut had stayed in an ISS-type spacecraft outside the magnetosphere during GLE 69, his SEP dose would have been approximately $8 \mathrm{mSv}$, as estimated by WASAVIES-EO (Sato et al. 2019). Considering the scaling factor of 119-141 mentioned before (Sect. "Aviation operation"), the SEP dose of an astronaut would exceed his/her career limit if a once-per-1000-year event occurred during a deep-space mission. Therefore, realtime monitoring of the radiation dose is indispensable in deep-space missions to take adequate action during a solar particle event, such as sheltering astronauts at well-shielded locations in their spacecraft (Mertens et al. 2018; Townsend et al. 2018). Note that the SEP doses of astronauts are expected to be much lower, by up to two orders of magnitude, when their spacecraft is in a lowEarth orbit (Sato et al. 2019).

An evacuation to a safe area of a spacecraft due to the occurrence of solar flares has been executed twice so far, in 1989 and 2003 (Kamide 2011). These events were near the peaks of the 22nd and 23rd solar cycles, respectively. Although no evacuation was executed during the 24th solar cycle when the overall solar activity was low, it is considered that cases of evacuation will occur approximately once per 11 years of solar activity. When a once-per-1000-year event occurs, in the worst case, an emergency return to Earth is expected. No clear analysis has been made for a once-per-100-year event, but as with a once-per-10-year event, evacuation to a safe area or an emergency return to Earth is expected.

\section{Daily life on the earth's surface}

Using WASAVIES, we estimated the cumulative SEP dose at sea level during GLE 69 to be $0.079 \mu \mathrm{Sv}$. Considering the scaling factor of 119-141 mentioned before (Sect. "Aviation operation"), the SEP dose for the public on the ground during a once-per-1000-year event is expected to be approximately $10 \mu \mathrm{Sv}$. This value is sufficiently low in comparison with the annual dose limitation for the public recommended by ICRP, i.e., $1 \mathrm{mSv}$. Therefore, radiation exposure to SEPs is not a potential hazard to the public on the ground, even considering the fact that the SEP dose increases with the altitude.

\section{Evaluation of economic impact}

To estimate the economic impact of space weather phenomena in Japan, we consider the impacts due to power outages and changing aviation routes. We choose these two fields as a first step because of their seriousness and less dependence on individual details. Since the latter is reported by Saito et al. (2021), only an outline is given.

\section{Electricity}

As mentioned in Sect. "Electricity", GIC damages the power grid and disrupts the power supply, which can affect industries that use power. Oughton et al. (2017) estimated the economic impact of blackouts caused by GIC for the United States.

The economic impact in the case of a power outage due to GIC in Japan was calculated using the inter-regional input-output table produced by the Ministry of Economy, Trade and Industry. The input-output table contains an index of the degree of influence between regions and industries, representing the quantities of different services and products produced in each region and what they are input into. The size of GIC events that can occur in Japan was discussed in Sect. "Electricity", while it is difficult at present to calculate the specific impact on substation facilities. Therefore, we estimated the economic impact assuming a power outage occurring in one area as a result of a strong local GIC flow due to an extreme phenomenon. According to the simulation results of Nakamura et al. (2018), in which an observed induced electric field was used as an input, the largest GIC tends to flow at a certain substation in the Kanto region. In other words, a substation facility in the Kanto region might be the most damaged by an extreme phenomenon. Therefore, we consider the case that the transmission of electricity in the Kanto region is stopped. Although the duration of power outage is expected to be longer for a larger magnetic storm, the amount of damage per day is estimated here in order to avoid a discussion of the duration.

According to the inter-regional input-output table in 2005 , the production value of the electric power industry in the Kanto region is 4,985,236 million yen per year. The direct loss is 13,649 million yen/day if the transmission of electricity in the Kanto region stops for one day. We estimated the economic impact on the upstream side, i.e., the production of raw materials, and the downstream side, where the generated electricity is used, when GIC suspends power transmission in the Kanto region and the demand for power disappears. The influence of the power industry in the Kanto region on other regions/industries on the upstream side is estimated using the inter-regional input-output table. As a result, it was estimated that the output demand of the Kanto region power industry would have a production ripple of about 675 million yen/ day if the power transmission in the Kanto region was stopped for one day. In addition, this would result in a direct loss of 9532 million yen/day to the downstreamside industry. The total of the above three figures is 23.8 billion yen/day, which is the estimation result obtained from the general input-output analysis.

On the other hand, a different input-output analysis method was used to estimate the economic impact in the 
interim report by the Working Group on Countermeasures against Natural Disasters of Electric Facilities (2014) for a similar situation. The input loss per day, 13,649 million yen, is the same as in the above estimation. They estimated the upstream ripple effect to be 3420 million yen/ day, the downstream ripple effect to be 2.59 billion yen/ day, and the indirect ripple effect to be 200 million yen/ day. The total of these values is about 19.8 billion yen/day.

Taking all of these findings into consideration, a loss of approximately 19.8 to 23.8 billion yen/day will occur due to a one-day suspension of power transmission in the Kanto region. Note that this calculation was based on the assumption that the electricity in the whole of the region is stopped for $24 \mathrm{~h}$; therefore, this could be an overestimation. In addition, the probability of such an event in Japan is extremely low according to the estimation in Sect. "Electricity". On the other hand, the estimation will contain uncertainty and the economic impact will be huge if it occurs. Considering the consistency with the GIC simulation results to improve the calculation accuracy of the economic impact is a future work.

\section{Aviation operation}

Section "Aviation operation" described the increased exposure risk for aircraft crews during SEP events. We evaluated the economic loss due to a change in the flight route to avoid exposure (Saito et al. 2021). Specifically, we considered restrictions on the flight altitude and latitude necessary for a safe flight path. The actual track of a North American route from New York to Narita, Japan was used as a reference route. This estimation considered a large GLE event, GLE 69, whose peak occurred at 06:55 UT on January 20, 2005. Assuming the moderate level threshold of $30 \mu \mathrm{Sv} / \mathrm{h}$ and the normal exposure dose of $10 \mu \mathrm{Sv} / \mathrm{h}$ determined from ICAO space weather information, we searched for aviation routes that did not exceed these thresholds during this GLE event. The changes in the flight distance, time, and fuel consumption due to the change in the route were estimated, and the economic impact was evaluated as the increase in the fuel cost.

On the normal New York-Tokyo route with the highest altitude of $10.972 \mathrm{~km}$, the maximum exposure dose rate was about $120 \mu \mathrm{Sv} / \mathrm{h}$ for the GLE 69-equivalent event. The maximum exposure dose rate was assumed to continue for the entire flight time for simplicity. An exposure dose rate of less than the $30 \mu \mathrm{Sv} / \mathrm{h}$ threshold at all locations on the flight path was achieved by (i) reducing the altitude of the flight path to less than $6.096 \mathrm{~km}$ without changing the horizontal route, or (ii) reducing the altitude of the flight path to less than $9.144 \mathrm{~km}$ and shifting the flight path equatorward to a latitude of $44^{\circ} \mathrm{N}$. Assuming the other conditions are the same as for the normal route, the increases in fuel consumption due to these two changes are 44,310 and $36,540 \mathrm{~kg}$ per flight for a large twin-engine jet airliner. This would cost 2.67-3.26 million yen assuming the aviation fuel price in February 2020 (Saito et al. 2021).

Monitoring and forecasting the progress of SEP events will enable restrictions to be relaxed and the flight path to return to a more efficient one during a flight, i.e., the increase in fuel consumption can be suppressed by utilizing space weather forecast information. In addition, this trial calculation was performed under the simplified condition that one limit value was given to the flight altitude with or without a change in latitude. Therefore, the economic impact obtained here should be considered as the upper limit in the worst case. To evaluate the effects on fuel consumption and flight time more realistically, it is necessary to search for the optimum flight route while considering the three-dimensional distribution of the exposure dose.

\section{Required research topics}

Table 3 lists the new issues that have been proposed from the compilation of the PSTEP report. In addition, the following points need to be examined as issues related to the overall impact of space weather phenomena on society:

1) A linear relationship is not always established between causal phenomena. For example, solar flares and their associated CMEs are qualitatively causal, while quantitatively large solar flares do not necessarily produce large-scale CMEs. On the other hand, there are also examples of large-scale social impacts caused by C-class solar flares, e.g., the St. Patrick event.

2) Space weather phenomena do not always occur solely, but multiple phenomena may occur within a short period, especially during high solar activity. In this case, even if each phenomenon is small, the impact on society may be increased due to a synergistic effect. For example, radio communication of aviation operation is usually available with several methods, e.g., HF, VHF, and satellite communications. We evaluate the effect of each space weather phenomenon and categorize them as yellow due to the existence of alternative methods in Table 2. If several phenomena occur simultaneously and no alternative methods are available, the effect could be "red". Statistical analysis for these cases is required. In addition, space weather phenomena of the same scale may have different effects on society due to the history of changes in the environment between the Sun and the Earth induced by recently occurring phenomena. 
Table 3 Required future research topics

\begin{tabular}{ll}
\hline Field & Effect \\
\hline Electricity & Black out
\end{tabular}

Electricity

Black out

Economic impact

Satellite operation

Spacecraft (surface charging)

Spacecraft (internal charging)

Spacecraft (single event upsets, deterioration of solar cells)

Atmospheric drag

Radio communication and broadcasting

Positioning

Aviation

Daily life on the Earth's surface
High-frequency (HF) hazard

Very high frequency (VHF) hazard

Communication failure

Poor positioning accuracy

Aircrew exposure

Electronic device soft errors

Economic impact

Astronaut exposure

Exposure on the ground

Electronic device soft errors

Malfunction of signal equipment

\section{Research topic}

GIC calculation based on highly accurate ionospheric and magnetospheric currents

Impact assessment considering the resistance of each substation and transformer

Consideration of not only the effect of the transformer itself, but also the possibility of triggering a domino effect, e.g., the blackout associated with the Hokkaido Eastern Iburi Earthquake

Improvement of the accuracy of estimation of economic impact including consistency with GIC simulation results

Clarification of the relationship between the development of surface electric charging with causal changes in the surrounding space environment

Risk assessment considering various conditions, e.g., satellite position and the timing of the substorm (i.e., the relative position of the region with increased high-temperature electrons associated with the substorm), the energy spectrum of the substorm high-temperature electrons, the attitude at that time, the discharge threshold specific to each satellite related to its design and materials, the estimated discharge frequency, and whether the satellite is located in sunshine or shade

More analysis of the space environment around satellites and the satellite surface charging environment using observed data

Verification of internal charging and discharging by experiments and simulations at the design stage

Quantitative evaluation of occurrence probabilities based on data analysis

Development of a model that can quantitatively evaluate (i) the amount of heating of the upper atmosphere due to solar ultraviolet emissions and magnetic storms and (ii) the accompanying effects on the orbit and attitude of satellites

Consideration of quantitative needs and seeds matching

Quantitative understanding of failure status and consideration of the causes

Creation of a real-time ionospheric global map by using worldwide ionospheric observation data

Same as above

Same as above

Development of technology to reinforce degraded satellite positioning signals

Creation of a protocol for changing routes and suspension of operations via discussion with users

Evaluation of standards determined by ICAO

Quantitative investigation of the effects of space weather phenomena on aircraft equipment required for the above evaluation

Formulation of a protocol for reducing exposure dose, e.g., the allowable exposure dose rate

Investigation of the correlation of exposure dose and dose rate with the GLE scale Ell and other indicators

Measurement of exposure dose by aircraft experiment and verification of model accuracy

Discussion of soft errors caused by SEPs in addition to galactic cosmic rays

Evaluation of the forecast accuracy and loss calculation used as a basis for determining whether space weather information is adopted

Development of a detector that measures the proton flux in spacecraft in real time

Development of a model estimating the astronaut exposure dose from the response of a detector

Investigation of the correlation between exposure dose and GLE size measured by the Ell index or other indicators

No specific topics

Discussion of soft errors caused by SEPs in addition to galactic cosmic rays

No specific topics 
3) The estimation accuracy of the impact of space weather phenomena on society and their occurrence time is not yet sufficient. Model development and precision improvement are required, as well as more accurate measurements for monitoring systems, e.g., the CME speed and plasma bubble occurrence. Models must be improved before they are able to realistically handle extreme input values.

4) It is necessary to quantitatively investigate the impact of space weather on industry to evaluate the social impact. During this PSTEP, discussions with many people from industry have been initiated, providing us with previously undisclosed information owing to the building of trust. However, discussions are still in the development stage, and continued interaction is essential in the future. In addition, these evaluations should be revisited and updated with the progress of social technologies.

\section{Summary}

We constructed space weather benchmarks by the following two steps. First, we evaluated different scales of each space weather phenomenon, covering solar flares, CME, SEPs, solar radio bursts, variation of the relativistic electron flux of the outer radiation belt, geomagnetic storms, substorms, and ionospheric disturbances, by reviewing previous research and conducting new analyses. Our scale was based on phenomena having an expected occurrence ranging from daily to once per 1 , 10,100 , and 1000 years. Then the effects of space weather on Japanese society were evaluated for different fields, covering electric power, satellite operation, communication/broadcasting, positioning use, aviation operation, manned space activity, and daily life on the Earth's surface.

We analyzed and discussed each phenomenon and social field separately, although each phenomenon resulted from a complicated interaction among solar activity, the magnetosphere, the ionosphere, phenomena on the ground, and society. If each space weather phenomenon could be reproduced by simulation and/or analyzed, including the interactions, a more detailed impact assessment would be realized. In the future, it will be necessary to solve the above-mentioned problems while continuing to conduct more accurate impact analysis and social impact assessment in collaboration with industries.

\section{Abbreviations}

ADS-B: Automatic dependent surveillance-broadcast; CIR: Corotating interaction region; CME: Coronal mass ejection; DOP: Dilution of precision; Ell: Event-integrated intensity; Es layer: Sporadic E-layer; FM: Frequency modulation; GCR: Galactic cosmic ray; GEO: Geostationary orbit; GEONET:
GPS Earth Observation NETwork; GIC: Geomagnetically Induced Current; GLE: Ground Level Enhancement; GNSS: Global Navigation Satellite System; GOES: Geostationary Operational Environmental Satellite; GPS: Global positioning system; HF: High frequency; ICAO: International Civil Aviation Organization; ICRP: International Commission on Radiological Protection; IDA: Institute for Defense Analyses; IMF: Interplanetary magnetic field; ISS: International Space Station; LASCO: Large Angle and Spectrometric Coronagraph experiment; MEO: Medium Earth orbit; MSH: Millionths of a solar hemisphere; MUF: Maximum usable frequency; PCA: Polar Cap Absorption; PSTEP: Project for SolarTerrestrial Environment Prediction; RNAV: Area Navigation; ROTI: Rate of TEC change index; SAA: South Atlantic Anomaly; SDO: Solar Dynamics Observatory; SEP: Solar Energetic Particle; SME: SuperMAG Electrojet; SOHO: Solar and Heliospheric Observatory; SWF: Short-wave fadeout; SWORM: Space Weather Operations, Research, and Mitigation; TEC: Total electron content; TECU: Total electron content unit; TID: Traveling ionospheric disturbances; UHF: Ultra-high frequency; UK: United Kingdom; US: United States; VHF: Very high frequency; WASAVIES: Warning System for AVlation Exposure to SEP; WASAVIES-EO: Warning System for AVlation Exposure to SEP extended to Earth Orbit.

\section{Acknowledgements}

GPS/GNSS data of GEONET were provided by the Geospatial Information Authority of Japan.

\section{Authors' contributions}

MI led this research. DS and CT compiled and edited the PSTEP report and this paper. KKu, KI, DS, and TI contributed to the discussion as experts of solar physics. YK contributed to the discussion as an expert of solar radio emission and space weather forecasting. YM and TN contributed to the analysis and discussion as experts of radiation belts. TS, RK, DS, YK, and SY contributed to the analysis and discussion as experts of SEPS and their effect on the environment and humans. YE conducted the analysis and discussion as an expert of the magnetosphere and GIC estimation. KKo, TN, MNa AN, and YM contributed to the discussion of the effect on satellite operation. MNi, TT, SS, CT, and HF contributed to the analysis and discussion as experts of the ionosphere and its social impacts. DS conducted the economic impact evaluation due to GCM, and SS conducted the economic impact evaluation in the aviation field. All authors read and approved the final manuscript.

\section{Funding}

This work was supported by MEXT/JSPS KAKENHI Grant $15 \mathrm{H} 05813$.

\section{Availability of data and materials}

The analysis in this paper used the datasets of radiation belt electrons (Sect. "Variations of relativistic electron flux of the outer radiation belt"), the magnetospheric SME index (Sect. "Substorms"), ionospheric observations by GNSS and ionosondes (Sects. "Sporadic E-layer (Es Layer)" and "Plasma bubbles"), and the inter-regional input-output table used to determine the economic impact of GIC (Sect. "Electricity"). The fluence of the radiation belt electrons analyzed in this study is based on differential flux data obtained from https:// www.ngdc.noaa.gov/stp/satellite/goes/dataaccess.html. The SME index used in this analysis is available from http://supermag.jhuapl.edu/indices/. TEC data are archived at NICT's website (https://aer-nc-web.nict.go.jp/GPS/GEONET/). Manually scaled ionosonde parameters are also at NICT's homepage (http:// wdc.nict.go.jp/IONO/HP2009/ISDJ/manual_txt.html). The inter-regional inputoutput table for economic factors was provided by the Ministry of Economy, Trade and Industry (https://www.meti.go.jp/statistics/tyo/tiikiio/result/result_ 02.html).

\section{Declarations}

Ethics approval and consent to participate

No applicable.

\section{Consent for publication}

No applicable.

\section{Competing interests}

The authors declare that they have no competing interests. 


\section{Author details}

${ }^{1}$ National Institute of Information and Communications Technology (NICT), Koganei, Tokyo, Japan. ${ }^{2}$ Kyoto University, Uji, Kyoto, Japan. ${ }^{3}$ Seikei University, Musashino, Tokyo, Japan. ${ }^{4}$ National Institute of Polar Research, Tachikawa, Tokyo, Japan. ${ }^{5}$ Japan Aerospace Exploration Agency, Tsukuba, Ibaraki, Japan. ${ }^{6}$ Nagoya University, Nagoya, Aichi, Japan. ${ }^{7}$ Osaka Prefecture University, Sakai, Osaka, Japan. ${ }^{8}$ Electronic Navigation Research Institute (ENRI), National Institute of Maritime, Port and Aviation Technology (MPAT), Chohu, Tokyo, Japan. ${ }^{9}$ Japan Atomic Energy Agency, Tokai, Ibaraki, Japan. ${ }^{10}$ Kyoto University, Kyoto, Japan.

Received: 10 September 2020 Accepted: 17 April 2021

Published online: 18 May 2021

\section{References}

Asvestari E, Willamo T, Gil A, Usoskin IG, Kovaltsov GA, Mikhailov VV, Mayorov A (2017) Analysis of ground level enhancements (GLE): extreme solar energetic particle events have hard spectra. Adv Space Res 60(4):781-787

Aulanier G, Démoulin P, Schrijver CJ, Janvier M, Pariat E, Schmieder B (2013) The standard flare model in three dimensions II. Upper limit on solar flare energy, Astron. Astrophys. 549:66

Davies K (1990) lonospheric Radio, Institution of Engineering and Technology Dennis BR (1985) Solar hard X-ray bursts. Solar Phys 100:465-490

Gopalswamy N (2018) Extreme solar eruptions and their space weather consequences. In: N. Buzulukova (ed) Extreme events in Geospace origins, Predictability, and consequences, Elsevier, pp 37-63, https://doi.org/10. 1016/C2016-0-03769-5

ICRP (2007) The 2007 Recommendations of the International Commission on Radiological Protection, ICRP Publication 103. Ann. ICRP 37:(2-4)

Jiggens P, Heynderickx D, Sandberg I, Truscott P, Raukunen O, Vainio R (2018) Updated model of the solar energetic proton environment in space. J Space Weather Space Climate 8:1-22

Kamide Y (2011) The mysterious relationship between the sun and the Earthabsolute monarch and helpless servant (in Japanese). Kodansha

Kappenman JG (2004) Space Weather and the Vulnerability of Electric Power Grids. In: Daglis IA (ed) Effects of Space Weather on Technology Infrastructure. NATO Science Series II: Mathematics, Physics and Chemistry, vol 176. Springer, Dordrecht, pp. 257-286. /https://doi.org/10.1007/1-40202754-0_14

Karasawa Y, Yasukawa K, Yamada M (1985) Ionospheric scintillation measurements at $1.5 \mathrm{GHz}$ in mid-latitude region. Radio Sci 29:643-651

Kelly MA, Comberiate JM, Miller ES, Paxton LJ (2014) Progress toward forecasting of space weather effects on UHF SATCOM after operation anaconda. Space Weather 12:601-611. https://doi.org/10.1002/2014SW001081

Klobuchar JA (1987) Ionospheric time-delay algorithm for single frequency GPS users. IEEE Trans. Aerospacee Elect System AES-23, 3:325-331.

Lantos P, Fuller N (2003) History of the solar particle event radiation doses onboard aeroplanes using a semi-empirical model and Concorde measurements. Radiat Prot Dosimetry 104(3):199-210

Li X, Temerin M, Baker DN, Reeves GD (2011) Behavior of MeV electrons at geosynchronous orbit during last two solar cycles. J Geophys Res 116:A11207. https://doi.org/10.1029/2011JA016934

Maeda R, Inuki H (1972) Magnitude of short-wave fade-out. J of Radio Res Lab 18(99):467-476

Maehara H, Shibayama T, Notsu S, Notsu Y, Nagao T, Kusada S, Honda S, Nogami D, Shibata K (2012) Superflares on solar-type stars. Nature 485:478-481. https://doi.org/10.1038/nature11063

Matéo-Vélez J-C, Sicard A, Payan D, Ganushkina N, Meredith NP, Sillanpäa I (2018) Spacecraft surface charging induced by severe environments at geosynchronous orbit. Space Weather 16:89-106. https://doi.org/10. 1002/2017SW001689

McKenna-Lawlor S (2014) Feasibility study of astronaut standardized career dose limits in LEO and the outlook for BLEO. Acta Astronaut 104:565-573

Mekhaldi F, Muscheler R, Adolphi F, Aldahan A, Beer J, McConnell JR, Possnert G, Sigl M, Svensson A, Synal HA, Welten KC, Woodruff TE (2015) Multiradionuclide evidence for the solar origin of the cosmic-ray events of $A D$ 774/5 and 993/4. Nat Commun. https://doi.org/10.1038/ncomms9611
Meredith NP, Horne RB, Isles JD, Rodriguez JV (2015) Extreme relativistic electron fluxes at geosynchronous orbit: analysis of GOES E > 2 MeV electron. Space Weather 13:170-184. https://doi.org/10.1002/2014SW001143

Mertens C, Slaba T, Hu S (2018) Active dosimeter-based estimate of astronaut acute radiation risk for real-time solar energetic particle events. Space Weather 16:1291-1316

Miyake F, Nagaya K, Masuda K, Nakamura T (2012) A signature of cosmic-ray increase in AD 774-775 from tree rings in Japan. Nature 486:240-242

Miyake F, Usoskin I, Poluianov S (2019) Extreme Solar Particle Storms: The Hostile Sun. Institute of Physics Publishing, Bristol

Miyoshi Y, Kataoka R (2005) Ring current ions and radiation belt electrons during geomagnetic storms driven by coronal mass ejections and corotating interaction regions. Geophys Res Lett 32:L21105. https://doi.org/10.1029/ 2005GL024590

Miyoshi Y, Kataoka R (2008) Flux enhancement of the outer radiation belt electrons after the arrival of streaminteraction regions. J Geophys Res. 113:A03S09. https://doi.org/10.1029/2007JA012506

Miyoshi Y, Kataoka R (2011) Solar cycle variations of outer radiation belt and its relationship to solar wind structure dependences. J Atmos Sol-Terr Phys 73(1):77-87

Miyoshi Y, Kataoka R, Kasahara Y, Kumamoto A, Nagai T, Thomsen MF (2013) High-speed solar wind with southward interplanetary magnetic field causes relativistic electron flux enhancement of the outer radiation belt via enhanced condition of whistler waves. Res. Let, Geophys. https://doi. org/10.1002/grl.50916,40,17:4520-4525

Nakamura M, Yoneda A, Oda M, Tsubouchi K (2015) Statistical analysis of extreme auroral electrojet indices. Earth Planets Space 67:153

Nakamura S, Ebihara Y, Fujita S, Goto T, Yamada N, Watari S, Omura Y (2018) Time domain simulation of geomagnetically induced current (GIC) flowing in 500-kV power grid in japan including a three-dimensional ground inhomogeneity. Space Weather 16(12):1946-1959

Newell PT, Gjerloev JW (2011) Substorm and magnetosphere characteristic scales inferred from the SuperMAG auroral electrojet indices. J Geophys Res 116:A12232

Nishioka M, Tsugawa T, Jin H, Ishii M (2017) A new ionospheric storm scale based on TEC and foF2 statistics. Space Weather 15:228-239. https://doi. org/10.1002/2016SW001536

Nishioka M, Saito S, Tao C, Shiota D, Tsugawa T, Ishii M (2021) Statistical analysis of ionospheric total electron content (TEC): estimation of extreme TEC in long term in Japan. Earth Planets Space 73:52. https://doi.org/10.1186/ s40623-021-01374-8

Nita GM, Gary DE, Lanzerotti LJ, Thomson DJ (2002) The peak flux distribution of solar radio bursts. Astrophys J 570:1

Notsu Y, Maehara H, Honda S, Hawley SL, Davenport JRA, Namekata K, Notsu S, Ikuta K, Nogami D, Shibata K (2019) Do Kepler superflare stars really include slowly rotating Sun-like star? Results using APO 35m telescope spectroscopic observations and Gaia-DR2 Data. Astrophys. J. 876(58):1-39

Oughton E, Skelton A, Horne R, Thomson A, Gaunt C (2017) Quantifying the daily economic impact of extreme space weather due to failure in electricity transmission infrastructure. Space Weather 15(1):65-83

Paulikas GA, Blake JB (1979) Effects of the solar wind on magnetospheric dynamics: energetic electrons at the synchronous orbit. In: Olson WP (ed) Quantitative Modeling of Magnetospheric, the American Geophysical Union, pp. 180-202. https://doi.org/10.1029/GM021p0180

Reep JW, Knizhnik KJ (2019) What determines the X-ray intensity and duration of a solar flare? Astrophys J 874(157):1-16

Reeves GD, Vandegriff EM, Niehof JT, Morley SK, Cunningham GS, Henderson MG, Larsen BA (2020) Defining radiation belt enhancement events based on probability distributions. Space Weather 18:e2020SW002528. https:// doi.org/10.1029/2020SW002528

Sakai J, Hosokawa K, Tomizawa I, Saito S (2019) A statistical study of anomalous VHF propagation due to the sporadic-E layer in the air-navigation band. Radio Sci 54:426-439. https://doi.org/10.1029/2018RS006781

Saito S, Wickramasinghe NK, Sato T, Shiota D (2021) Estimate of economic impact of solar energetic particle events on aircraft operations. Earth Planet Space 73:57. https://doi.org/10.1186/s40623-021-01377-5

Sato T, Kataoka R, Shiota D, Kubo Y, Ishii M, Yasuda H, Miyake S, Park I, Miyoshi Y (2018a) Real-Time and Automatic Analysis Program for WASAVIES: warning system for aviation exposure to solar energetic particles. Space Weather 16:924-936 
Sato T, Nagamatsu A, Ueno H, Kataoka R, Miyake S, Takeda K, Niita K (2018b) Comparison of cosmic-ray environments on Earth, Moon, Mars, and spacecraft using PHITS. Radiat Prot Dosim 180:146-149

Sato T, Kataoka R, Shiota D, Kubo Y, Ishii M, Yasuda H, Miyake S, Miyoshi Y, Ueno H, Nagamatsu A (2019) Nowcast and forecast of galactic cosmic ray $(G C R)$ and solar energetic particle (SEP) fluxes in magnetosphere and ionosphere-extension of WASAVIES to Earth orbit. J Space Weather Space Climate 9:1-11

Sauer HH, Wilkinson DC (2008) Global mapping of ionospheric HFNHF radio wave absorption due to solar energetic protons. Space Weather 6(1-9):S12002. https://doi.org/10.1029/2008SW000399

Swiss Re (2014) Space weather impacts a risk to society? Economic aspects from an Insurance/Reinsurance Point of View. https://www.swpc.noaa. gov/sites/default/files/images/u33/NOAA-MASTER.pdf

Tabata Y, Ogawa S (2003) Measurement and prediction of geomagnetically induced current (in Japanese), conference paper of the Institute of Electrical Engineers of Japan. https://ieej.ixsq.nii.ac.jp/ej/?action=pages_ view_main\&active_action=repository_view_main_item_detail\&item_ $i d=19645 \&$ item_no $=1 \&$ page_id $=13 \&$ block_id $=1 \overline{8}$

Tao C, Nishioka M, Saito S, Shiota D, Watanabe K, Nishizuka N, Tsugawa T, Ishii M (2020) Statistical analysis of short-wave fadeout for extreme event estimation. Earth Planet Space 72:173. https://doi.org/10.1186/ s40623-020-01278-z

The Institute of Applied Energy (2015), Survey report on electrical equipment technical standards and related services (in Japanese), NEC Technical Standards Compliance Evaluation Committee

Townsend LW, Adams JH, Blattnig SR, Clowdsley MS, Fry DJ, Jun I, McLeod CD, Minow Jl, Moore DF, Norbury JW, Norman RB, Reames DV, Schwadron NA, Semones EJ, Singleterry RC, Slaba TC, Werneth CM, Xapsos MA (2018)
Solar particle event storm shelter requirements for missions beyond low Earth orbit. Life Sci Space Res 17:32-39

Tsubouchi K, Omura Y (2007) Long-term occurrence probabilities of intense geomagnetic storm events. Space Weather 5:S12003

UK Cabinet office (2015) Space Weather Preparedness Strategy. https://assets.publi shing.service.gov.uk/government/uploads/system/uploads/attachment_ data/file/449593/BIS-15-457-space-weather-preparedness-strategy.pdf

US National Science and Technology Council (2015a) Space Weather Action Plan. https://www.sworm.gov/publications/2015/swap_final_20151 028.pdf

US National Science and Technology Council (2015b) National Space Weather Strategy. https://www.whitehouse.gov/sites/default/files/microsites/ ostp/final_nationalspaceweatherstrategy_20151028.pdf

US National Science and Technology Council (2018) Space Weather Phase 1 Benchmarks. DIALOG https://www.whitehouse.gov/wp-content/uploa ds/2018/06/Space-Weather-Phase-1-Benchmarks-Report.pdf

US Science and Technology Policy Institute (2019) Next Step Space Weather Benchmarks. https://www.ida.org/-/media/feature/publications/n/ne/ next-step-space-weather-benchmarks/gr-10982.ashx

Vasyliunas V (2011) The largest imaginable magnetic storm. J Atmos Sol-Terr Phys 73(11-12):1444-1446

Working Group on Countermeasures against Natural Disasters of Electric Facilities (2014) Interim report (in Japanese). https://www.meti.go.jp/shing ikai/sankoshin/hoan_shohi/denryoku_anzen/denki_setsubi/20140624_ report.htm

\section{Publisher's Note}

Springer Nature remains neutral with regard to jurisdictional claims in published maps and institutional affiliations.

\section{Submit your manuscript to a SpringerOpen ${ }^{\circ}$ journal and benefit from:}

- Convenient online submission

- Rigorous peer review

- Open access: articles freely available online

- High visibility within the field

- Retaining the copyright to your article

Submit your next manuscript at $\boldsymbol{\nabla}$ springeropen.com 